\title{
The impact of body mass index on short-term and long-term surgical outcomes of laparoscopic hepatectomy in liver carcinoma patients, a retrospective study
}

\section{Lei Zhao}

Zhejiang University School of Medicine Sir Run Run Shaw Hospital

\section{Gang Jian Wang}

Hangzhou Emergency Medical Center

Jingxia Kong

Zhejiang Financial College

\section{Xing Zhen}

Zhejiang University School of Medicine Sir Run Run Shaw Hospital

Xin Yu ( $\nabla$ xinxin_yu@zju.edu.cn )

Zhejiang University School of Medicine Sir Run Run Shaw Hospital

\section{Research article}

Keywords: body mass index, liver carcinoma, Prognosis, laparoscopic hepatectomy

Posted Date: April 27th, 2020

DOI: https://doi.org/10.21203/rs.3.rs-24269/v1

License: (c) (1) This work is licensed under a Creative Commons Attribution 4.0 International License.

Read Full License 


\section{Abstract}

Background: To investigate the influence of body mass index (BMI) on the short-term and long-term outcomes including disease free survival (DFS) and overall survival (OS) rate in patients with liver carcinoma who underwent laparoscopic hepatectomy $(\mathrm{LH})$ as primary treatment.

Methods: Data were collected from 137 patients with liver carcinoma who underwent attempted LH between August 2003 and April 2014. Patients were classified into three groups depending on their BMI according to the WHO's definition of obesity for Asia-Pacific region: underweight (BMK $18.5 \mathrm{~kg} / \mathrm{m}^{2}$, Group1), normal (18.5 $\leq$ BMl $<23 \mathrm{~kg} / \mathrm{m}^{2}$, Group2), overweight (BMI $\geq 23 \mathrm{~kg} / \mathrm{m}^{2}$, Group3) respectively. Shortterm and long-term outcomes including overall survival (OS) and disease free survival (DFS) were compared across the BMI categories.

Results: Of the 137 patients, 14 were underweight, 65 were normal weight, and 58 were overweight. The overall conversion rate of 137 patients was $20.44 \%$. Conversion rate in the three groups was $14.29 \%$, $21.54 \%$ and $20.69 \%$ ( $P=0.8284)$. The median follow-up duration was 26 months, 30 months, and 28 months, respectively. The mean postoperative hospital stay in the three groups were comparable $(10.85 \pm 4.04,11.57 \pm 5.56$, and $10.88 \pm 5.70, P=0.76)$. The complications rate was much higher in Group 1 (42.85\%) than that in Group 2 and Group $3(20.08 \%$ and $17.2 \%, P=0.048)$. Underweight patients were more likely to develop grade III or higher postoperative complications (Clavien-Dindo classification) as compared to normal and overweight patients $(P=0.042)$. Overweight patients had a longer 3 - and 5 -years DFS $(41.4 \%, 36.2 \%)$ than those for underweight $(21.4 \%, 14.3 \%)$ and normal weight $(28.1 \%, 21.9 \%)$ patients $(P=0.048$, and 0.025$)$. Overweight patients had a longer 5 -years OS $(44.8 \%)$ than those for underweight $(28.6 \%)$ and normal weight $(28.0 \%)$ patients $(P=0.043)$.

Conclusions: Being underweight was associated with an increased perioperative complication and being overweight has a better 3-, 5-years DFS and 5-years OS than those in under and normal weight patients with liver carcinoma who underwent LH.

\section{Background}

Liver carcinoma is one of the most maligancy cancers in the worldwide and has a particularly high incidence rate in Asian countries. Liver resection is the major way in the treatment of liver cancer and the potential advantage of laparoscopy has been identified such as less surgically invasive, fewer complications, and shorter intraoperative hospital stay (1.2). However, the prognosis still remains very poor (3.4). Factors such as age, tumor size and tumor number, pathologic TNM stage, vascular invasion et al have been identified to influence the prognosis for liver cancer patients (5-7). And now several researchers have found overweight status would increase $17 \%$ risk of HCC and obese status would even increase $90 \%$ risk of HCC compared with normal weight individuals $(8,9)$ However, the relationship between weight and prognosis of laparoscopic hepatectomy for liver carcinoma remains unclear. 
Body mass index $\left(\mathrm{BMl} ; \mathrm{kg} / \mathrm{m}^{2}\right)$ is a convenient and simple surrogate measure of body fat distribution in clinical setting. And the BMI values used to detect overweight and obese status recommended by the World Health Organization ( $>25 \mathrm{~kg} / \mathrm{m}^{2}$ ) were higher than those suggested by Asian population-based studies $(22-25 \mathrm{~kg} / \mathrm{m} 2)(10-11)$. The Working Group on Obesity in China has identified that BMI of 23 is the most sensitive and specific indicator for overweight status of Chinese people (12). Therefore, it is useful to evaluate the association between the prognosis of liver carcinoma and overweight defined by this $\mathrm{BMI}$ value.

The prognosis of liver cancer remains unsatisfactory. Survival rates at 6, 12, 24 months after initial diagnosis have been reported to be $44.1 \%, 21.7 \%$, and $14.2 \%$, respectively (13). Many studies focused on the Child Pugh score, a-fetoprotein (AFP) concentration to determine the prognosis of liver cancer $(14,15)$. But the data concerned influence of underweight and overweight status on this disease has yet to be undefined. The purpose of this study was to assess the effects of weight using BMI on relevant perioperative complications and the overall and disease free survival rate in patient with liver carcinoma who underwent laparoscopic hepatectomy.

\section{Methods}

\section{Patients and Diagnosis}

Patient selection. A retrospective cohort study that spanned an 11-year period from August 2003 to April 2014 was performed. 137 patients who underwent laparoscopic hepatectomy for liver carcinoma at our institution were identified. Institutional Review Board approval for this review was obtained from the Sir Run Run Shaw hospital of Zhejiang University.

According to the WHO's definition of obesity for the Asia-Pacific region, patients were divided into three groups by BMI: underweight $<18.5 \mathrm{~kg} / \mathrm{m}^{2}$ (Group 1), normal weight $18.5-23 \mathrm{~kg} / \mathrm{m}^{2}$ (Group 2), overweight $>23 \mathrm{~kg} / \mathrm{m}^{2}$ (Group 3) (16). BMI was calculated according to a standardized definition as weight in kilograms divided by height in meters squared and BMI was recorded the day before the surgery.

The diagnosis of liver carcinoma was established using imaging (enhanced computed tomography(CT) or magnetic resonance imaging (MRI)) and pathology reports.

All patients were followed up until February 2019,and the median follow-up duration was 27 months (range, 2 months).

\section{Surgical Technique}

Laparoscopic liver resection was performed as previously described (17). Regional occlusion of liver left/right inflow and outflow instead of total hepatic vascular occlusion was used to minimize liver ischemia reperfusion injury [16]. In the early years of the study (2003-2006), parenchymal transection of 
the liver was achieved with LPMOD (Peng's multifunction operative dissector, SY-IIIB, Hangzhou ShuYou Medical Equipment Co., Ltd, China) technique. Since 2007, the ultrasonic aspirator (CUSA; Valleylab, Boulder, Colo) has been used for most cases. If there were unclear tumor margin, uncontrolled bleeding, embolism, severe adhesion or other complications, laparoscopic procedure would be changed to open hepatectomy.

\section{Follow-up And Analysis}

After being discharged from the hospital, all patients had been followed up monthly within the first year. The follow-up included physical examinations, computed tomographic scan or magnetic resonance imaging scan, and alpha-feto-protein (AFP) et al. If no recurrence were detected, we would extend the follow-up to a quarterly cadence. Recurrence was defined as new typical features of mass on imaging, or a rising AFP level. Biopsy was performed when necessary.

Survival was defined as the interval from the date of diagnosis of liver cancer to the date of death or the last visit before February 2019.

\section{Data analysis}

Comparisons between groups were performed with the chi-square test for categorical variables and the Mann-Whitney U-test for continuous variables. DFS and OS were calculated by Kaplan Meier analysis, and the results for subgroups of patients were compared with log-rank test. $P<0.05$ was regarded as statistically significant. All statistical analyses were performed using the SPSS 13.0.

\section{Results}

A total of 137 patients was included in the study. Among them, 14 patients $(10.22 \%)$ were underweight, 65 patients (47.45\%) were normal weight and 58 patients (42.34\%) were overweight. The basic demographics and tumor characteristics between three groups are summarized in Table 1. The mean body mass index of patients in Group 1, Group 2, and Group 3 were $17.43 \pm 1.08,21.29 \pm 1.22$, and 25.38 \pm 2.68 , respectively. Other variables, including age, gender, Child-Pugh score, ASA score, liver cirrhosis, tumor size, tumor number, and the tumor stage have no significant difference between the three groups. 
Table 1

Demographics, pathological and surgical variable by BMI level of patients with liver cancer

\begin{tabular}{|c|c|c|c|c|c|}
\hline Variable & $\begin{array}{l}\text { All } \\
N=137\end{array}$ & $\begin{array}{l}\text { Underweight } \\
N=14\end{array}$ & $\begin{array}{l}\text { Normal } \\
\text { weight } \\
\mathrm{N}=65\end{array}$ & $\begin{array}{l}\text { Overweight } \\
N=58\end{array}$ & $\begin{array}{l}P \\
\text { value }\end{array}$ \\
\hline Age(years) & $56.35 \pm 13.24$ & $56.71 \pm 15.40$ & $54.98 \pm 13.67$ & $57.79 \pm 12.24$ & 0.5020 \\
\hline Female/Male & $97 / 40$ & $10 / 4$ & $47 / 18$ & $40 / 18$ & 0.9192 \\
\hline $\begin{array}{l}\text { ASA score }((1- \\
2) /(3-4))\end{array}$ & $117 / 20$ & $11 / 3$ & $56 / 9$ & $50 / 8$ & 0.7469 \\
\hline Child-Pugh score & $120 / 17$ & $13 / 1$ & $58 / 7$ & $49 / 9$ & 0.5964 \\
\hline Liver cirrhosis & $105 / 32$ & $13 / 1$ & $46 / 19$ & $46 / 12$ & 0.1704 \\
\hline Album g/dl & $3.7 \pm 0.52$ & $3.3 \pm 0.46$ & $3.84 \pm 0.61$ & $3.93 \pm 0.66$ & 0.048 \\
\hline Tumor size & $3.93 \pm 2.06$ & $4.29 \pm 2.89$ & $4.21 \pm 2.04$ & $3.53 \pm 1.81$ & 0.1528 \\
\hline Tumor number & $\begin{array}{l}\text { Mean: } 1.29 \pm \\
0.75, \\
\text { median:1 }\end{array}$ & $\begin{array}{l}\text { Mean: } 1.29 \pm \\
0.83, \\
\text { median:1 }\end{array}$ & $\begin{array}{l}\text { Mean: } 1.32 \pm \\
0.79, \\
\text { median:1 }\end{array}$ & $\begin{array}{l}\text { Mean: } 1.26 \pm \\
0.69, \\
\text { median:1 }\end{array}$ & 0.8663 \\
\hline Tumor & & & & & 0.933 \\
\hline Cholangiocarcinoma & 9 & 1 & 5 & 3 & \\
\hline $\begin{array}{l}\text { Hepatocellular } \\
\text { carcinoma }\end{array}$ & 99 & 9 & 46 & 44 & \\
\hline Adenocarcinoma & 10 & 2 & 6 & 2 & \\
\hline Metastatic hepatic & 19 & 2 & 8 & 9 & \\
\hline UICCT & 47 & $5(35.7 \%)$ & $22(33.8 \%)$ & $19(32.8 \%)$ & 0.822 \\
\hline Stage I & 63 & $5(35.7 \%)$ & $31(47.7 \%)$ & 27 (46.6\%) & \\
\hline Stage II & 16 & $1(7.1 \%)$ & $7(10.8 \%)$ & $8(12.0 \%)$ & \\
\hline Stage IIIA & 9 & $2(14.3 \%)$ & $4(6.2 \%)$ & $4(6.90 \%)$ & \\
\hline Stage IIIB & 2 & $1(7.1 \%)$ & $1(1.54 \%)$ & $0(0)$ & \\
\hline Stage IIIC & & & & & \\
\hline
\end{tabular}




\begin{tabular}{|llllll|}
\hline Variable & All & Underweight & $\begin{array}{l}\text { Normal } \\
\text { weight } \\
\mathbf{N}=\mathbf{6 5}\end{array}$ & $\begin{array}{l}\text { Overweight } \\
\mathbf{N}=\mathbf{5 8}\end{array}$ & $\begin{array}{l}\mathbf{P} \\
\text { value }\end{array}$ \\
\hline $\begin{array}{l}\text { Extent of live } \\
\text { resection }\end{array}$ & 41 & $4(28.57 \%)$ & $16(24.6 \%)$ & $21(36.20 \%)$ & 0.102 \\
$\begin{array}{l}\text { Wedge n (\%) } \\
\begin{array}{l}\text { Segmentectomy n } \\
(\%)\end{array}\end{array}$ & 70 & $6(42.86 \%)$ & $35(53.9 \%)$ & $29(50 \%)$ & \\
$\begin{array}{l}\text { Hemihepatectomy } n \\
(\%)\end{array}$ & 26 & $4(28.57 \%)$ & $14(21.53 \%)$ & $8(13.79 \%)$ & \\
\hline
\end{tabular}

\section{Short-term Outcomes And Complications}

Table 2 displays the perioperative and postoperative outcomes of the three groups. The conversion rate in the three groups were $16.67 \%, 27.45 \%$, and $26.09 \%(P=0.8284)$, respectively. The mean postoperative hospital length of stay for the three groups was $10.85 \pm 4.04$ days, $11.57 \pm 5.56$ days, and $10.88 \pm 5.7$ days $(P=0.7615)$, respectively. Notably, the overall complication rate in the underweight group was much higher than that in the normal weight and overweight groups ( $42.85 \%$ vs $23.08 \%$ vs $17.2 \%, P=0.048$, respectively). And for the postoperative complications, underweight patients developed grade III or higher of the Clavien-Dindo classification more easily than the other two groups $(P=0.042)$. In cohort group, bile leak was the most frequent postoperative complication, followed by intraabdominal sepsis, ascites, as well as pneumonia. 
Table 2

Perioperative and postoperative outcomes by BMI level of patients with liver cancer

\begin{tabular}{|c|c|c|c|c|c|}
\hline Variable & All & Underweight & $\begin{array}{l}\text { Normal } \\
\text { weight }\end{array}$ & Overweight & $\begin{array}{l}\mathrm{P} \\
\text { value }\end{array}$ \\
\hline $\begin{array}{l}\text { Estimated blood loss } \\
(\mathrm{ml}, \text { mean } \pm \mathrm{SD})\end{array}$ & $\begin{array}{l}558.28 \pm \\
778.34\end{array}$ & $\begin{array}{l}601.43 \pm \\
475.59\end{array}$ & $\begin{array}{l}631.60 \pm \\
916.61\end{array}$ & $\begin{array}{l}465.69 \pm \\
659.71\end{array}$ & 0.4899 \\
\hline Blood transfusion & $1.03 \pm 2.26$ & $0.96 \pm 1.50$ & $1.27 \pm 2.71$ & $0.78 \pm 1.82$ & 0.4949 \\
\hline Conversion $(\mathrm{Y} / \mathrm{N})$ & $28 / 109$ & $2 / 12$ & $14 / 51$ & $12 / 46$ & 0.8284 \\
\hline $\begin{array}{l}\text { Operative Time (min, } \\
\text { mean } \pm \text { SD) }\end{array}$ & $\begin{array}{l}161.47 \pm \\
101.39\end{array}$ & $\begin{array}{l}161.93 \pm \\
110.11\end{array}$ & $\begin{array}{l}176.43 \pm \\
119.66\end{array}$ & $\begin{array}{l}144.60 \pm \\
71.70\end{array}$ & 0.2221 \\
\hline $\begin{array}{l}\text { Postoperative length of } \\
\text { stay (D) }\end{array}$ & $11.20 \pm 5.46$ & $10.85 \pm 4.04$ & $11.57 \pm 5.56$ & $10.88 \pm 5.70$ & 0.7615 \\
\hline Complication & $30 / 137$ & $\begin{array}{l}6 / 14 \\
(42.85 \%)\end{array}$ & $\begin{array}{l}15 / 65 \\
(23.08 \%)\end{array}$ & $\begin{array}{l}10 / 58 \\
(17.2 \%)\end{array}$ & 0.048 \\
\hline Bile leak & $9 / 137$ & $2 / 14$ & $4 / 65$ & $3 / 58$ & 0.037 \\
\hline Introabodominal sepsis & $6 / 137$ & $1 / 14$ & $3 / 65$ & $2 / 58$ & 0.432 \\
\hline Surgical site infection & $3 / 137$ & $0 / 14$ & $2 / 65$ & $1 / 58$ & 0.737 \\
\hline Ascites & $5 / 137$ & $2 / 14$ & $3 / 65$ & $0 / 58$ & 0.032 \\
\hline Pneumonia & $5 / 137$ & $1 / 14$ & $2 / 65$ & $2 / 58$ & 0.758 \\
\hline bleeding & $3 / 137$ & $0 / 14$ & $1 / 65$ & $2 / 58$ & 0.647 \\
\hline Clavien classification & 26 & 4 & 12 & 10 & 0.732 \\
\hline $\begin{array}{l}\text { I-II } \\
\text { III-IV }\end{array}$ & 4 & 1 & 2 & 1 & 0.042 \\
\hline Chemotherapy & 57 & $4 / 14$ & $26 / 65$ & $27 / 58$ & 0.442 \\
\hline
\end{tabular}

\section{Long-term Outcomes}

The median follow-up durations in the three groups were 26 months, 30 months and 28 months, respectively. The DFS and OS of the cohort are shown in Table 3. The overall 90-day mortality was $1.46 \%$, and there was no difference between the three groups. The median disease free survival duration of Group 1, 2, and 3 were 28.71 months, 28.08 months, and 33.83 months, respectively. There was no significant difference of 1-year DFS between the three groups $(p=0.24)$. But as for the 3 - and 5-year DFS, overweight patients had a longer 3 - and 5-years DFS (41.4\%, 36.2\%) than underweight $(21.4 \%, 14.3 \%)$ and normal weight $(28.1 \%, 21.9 \%)$ patients $(P<0.05)$. Likewise, the median OS of the three groups were 32.14 , 32.43 , and 37.09, respectively. And there was no significant difference of 1-, 3-, and 5-year OS between the 
three groups. As to the 5- year OS, overweight patients had a trended of longer 5-year OS (40.8\%) than underweight $(28.6 \%)$ and normal weight $(28.1 \%)$ patients, but it did not reach statistics significance $(\mathrm{P}>$ 0.05).

Table 3

Body mass index and oncological outcome by BMI level of patients with liver cancer

\begin{tabular}{|lllll|}
\hline Variable & Underweight & Normal weight & Overweight & P value \\
\hline 90-day mortality, $\mathrm{n}(\%)$ & $0(0)$ & 2 & $0(0)$ & 0.325 \\
\hline Medium monthes, (M) & 28.71 & 28.08 & 33.83 & 0.291 \\
\hline 95\%Cl & $18.32-39.11$ & $22.53-33.63$ & $27.68-39.98$ & \\
\hline 1-year DFS & 57.1 & 53.1 & 62.1 & 0.274 \\
\hline 3-year DFS & 21.4 & 28.1 & 41.4 & 0.048 \\
\hline 5-year DFS & 14.3 & 21.9 & 36.2 & 0.025 \\
\hline 1-year OS & 92.3 & 93.7 & 89.7 & 0.337 \\
\hline 3-year OS & 57.1 & 69.8 & 72.4 & 0.207 \\
\hline 5-year OS & 28.6 & 28.1 & 40.8 & 0.053 \\
\hline
\end{tabular}

\section{Discussion}

Laparoscopic hepatectomy has become a feasible option for patients with liver malignancy. As a new technique, researchers have given more attention to short-term and long-term outcomes. Although being overweight and obese does not preclude one to laparoscopy (16), still little is known about the influence of recipient $\mathrm{BMI}$ on the long-term outcomes especially the recurrence rate and the overall survival rate after LH for HCC. In the present study, we observed the patients with elevated BMI accounted for $42.33 \%$. General surgeon will encounter more and more overweight and obese patients with liver cancer in the future. Therefore, it is important to fully understand the effect of elevated BMI on these patients. We carried out this retrospective analysis using our institutional database and we have shown that: (i) being overweight did not increase the conversion rate; (ii) being underweight is associated with an increased number and more severe complications; (iii) being overweight is associated with lower 3- and 5-years tumor recurrence, and being underweight is associated with higher 3- and 5-years tumor recurrence. (iv) being either underweight, normal weight, or overweight had a comparable 1-year and 3-year overall survival rate. But as to 5-years OS, being overweight had a higher chance of survival. It was interesting to detect that being overweight did not have any negative impact on prognosis after $\mathrm{LH}$ for liver carcinoma. Actually, a significant protective effect of overweight was observed for perioperative complications and tumor recurrence. Meanwhile, being underweight increased risk of perioperative complications and tumor recurrence. 
Many studies have demonstrated that the increased BMI would increase the risk of laparoscopic conversion rate and prolong operative time $(18,19)$ and thus the surgeons tended to be reluctant to perform laparoscopic surgery for overweight patients. However, there were no difference of conversion rate and operative time across the three groups in our study, which was consistent with Troisi et al. analysis (20). This may be because that all laparoscopic procedures were performed by same experienced surgeon team who have finished the learned curve and were capable enough to perform liver tumor using laparoscopic skill, and also there were no patients' BMI more than 40 . Meanwhile, not in line with previous studies, which found that overweight patients had a worse outcome than their leaner counterparts (21), our results showed that overweight patients had a lower complication rate $(17.2 \%)$ compared to the underweight (42.85\%) and normal weight patients (23.08\%), the decreased BMI values was a risk factor for higher incidence of postoperative complications. We also found severe complications for grade III to IV according to the Clavien classification were much higher in underweight group than that in normal weight and overweight group. One cause may be overweight patients are protected by adequate fat storage, better nutrition, and systemic insulin resistance that underweight people do not have (22), Meanwhile the patients with a preoperative lower BMI is more likely to indicate the excessive nutritional consumption and malnutrition resulting from more aggressive tumor (23).

To our knowledge, little research has investigated the association between BMI and prognosis in patients undergoing LH with liver cancer. Yeuh-Shih Chang al reported overweight status had better oncologic outcomes following hepatectomy in HCC patients (24), but the end point of Chang's study was 6-month of survival. The follow-up duration was relatively short, and more data were needed on the overall survival rate as an important therapeutic measure of liver cancer if treatment intensity and life expectancy were judged (25). Our study aimed to verify long-term outcome of liver carcinoma patients who underwent LH, and our data revealed underweight patients had much higher 3- and 5-years cumulative tumor recurrence rate than that in the other two groups. As we know that liver tumors are a consumptive disease, a higher proportion of later stage (stage III) in underweight group in our study was the main cause of a worse outcome. Underweight patients may be malnutrition, possible immune deficiency and then cannot withstand the hepatic resection coupled with other therapies. Also, weight loss or low serum albumin levels of liver disease would be contributed to the high postoperative complications and high 3-and 5years DFS. Our result showed overweight had a better 3- and 5-years DFS and had a tendency of longer 5years overall survival rate. $\mathrm{BMI} \geq 23 \mathrm{~kg} / \mathrm{m}^{2}$ is a direct indicator for Asian patients with liver cancer who may benefit from more aggressive anticancer treatment to reduce the tumor recurrence. But as to the overall survival rate, it was comparable between the three groups. Chronic disorders such as cardiovascular disease, hypertension and diabetes, which are closely related to obesity will increase the risk of physical disability and mortality rates in the long run (26). It is reported that nearly $70 \%$ of deaths related to high BMI are due to cardiovascular disease and over $60 \%$ of those deaths occurs among the obese patients (27). In our study, the high BMI related morality also increased the OS, thus lose the advantage of low tumor recurrence of the overweight group. 
Even more, it has been previously reported that postoperative complications had a negative impact on the tumor recurrence and long-term survival rate, especially for severe postoperative complications (28). In our study, we again verified that postoperative complication may have an effect on the prognosis of liver cancer patients. We found underweight patients suffered more complications and had a worse DFS. One reason is that the surgical trauma and tissue damage of the complications could result in the immune suppression, and in turn increase the possibility of immune escape and tumor progression $(29,30)$. Secondly, large number of cytotoxic mediators from inflammatory response caused by the infected complications could provide a microenvironment for the growth and invasion of tumor cells, and further promote the development of tumor recurrence (31). At the same time, minimally invasive laparoscopic surgery could avoid the complications such as poor wound healing and pulmonary infection caused by long incision, which brought more advantages for overweight patients.

This study has some limitations. First, this was a retrospective, non-randomized survey that may have suffered from selection bias. Second, this was a single-center study and there is still no standard treatment for liver cancer. Our results might have been influenced by our surgical strategy. Thirdly, we only used BMI to estimate obesity, which was not enough to assess the abdominal adiposity of Asian people.

\section{Conclusion}

Our data showed that laparoscopic approach to treat overweight patients with hepatocellular carcinoma is feasible and safe. Overweight has a proactive effect for perioperative complications and tumor occurrence and it should not deter a surgeon for selection the LH for patients with liver malignance.

\section{Abbreviations}

BMI: body mass index; LH: Laparoscopic hepatectomy; DFS: Disease free survival; OS: Overall survival; LPMOD: Peng's multifunction operative dissector; CT: enhanced computed tomography; MRI: magnetic resonance imaging; AFP: alpha-feto-protein.

\section{Declarations}

\section{Ethics Approval and consent to participate}

This study was reviewed and approved by the institutional Ethical Board of Sir Run Run Shaw Hospital of Zhejiang University. And the need for informed consent was waived due to the retrospective nature of the study.

\section{Consent to publish}

Not applicable

\section{Availability of data and materials}


The datasets generated and analyzed during the current study are available from the corresponding author.

\section{Competing interests}

The authors declare that they have no competing interests and no financial relationship with other organizations sponsoring this research.

\section{Funding}

The work was supported by the fund of public health bureau of Zhejiang Province (2016KYA152) which was awarded to Dr. ZhenXing.

The funding sources have no role in study design, data collection, analysis, interpretation and the writing of the manuscript.

\section{Authors' Contributions}

ZL performed the statistical analysis and drafted the manuscript. WJG and ZX conducted the study and managed the database. YX participated in its design and drafted the manuscript. All authors have read and approved the final manuscript.

\section{Acknowledgements}

The authors would like to thank LiQingQuan for assistance with the statistics analysis. And the first two authors contribute equally to the study.

\section{References}

1. Morise Z, Ciria R, Cherqui D, et.al. Can we expand the indications for laparoscopic liver resection? A systematic review and meta-analysis of laparoscopic liver resection for patients with hepatocellular carcinoma and chronic liver disease. J Hepatobiliary Pancreat Sci 2015; 22: 342-52. 『

2. Kim H, Suh KS, Lee KW, et.al. Long-term outcome of laparoscopic versus open liver resection for hepatocellular carcinoma: a case-controlled study with propensity score matching. Surg Endosc 2014; 28: 950-60.

3. Poon RT, Fan ST. Hepatectomy for hepatocellular carcinoma: patient selection and postoperative outcome. Liver Transpl 2004; 10:39-45.

4. Pawlik TM, Poon RT, Abdalla EK, et.al. International Cooperative Study Group on Hepatocellular Carcinoma.Critical appraisal of the clinical and pathologic predictors of survival after resection of large hepatocellular carcinoma. Arch Surg 2005; 140:450-7.

5. Esnaola NF, Mirza N, Lauwers GY, et.al. Comparison of clinicopathologic characteristics and outcomes after resection in patients with hepatocellular carcinoma treated in the United States, 
France, and Japan. Ann Surg 2003; 238:711-9.

6. Pawlik TM, Delman KA, Vauthey JN, et.al. Tumor size predicts vascular invasion and histologic grade: implications for selection of surgical treatment for hepatocellular carcinoma. Liver Transpl 2005;11: 1086-92.

7. Regimbeau JM, Abdalla EK, Vauthey JN, et.al. Risk factors for early death due to recurrence after liver resection for hepatocellular carcinoma: results of a multicenter study. J Surg Oncol 2004; 85:36-41.

8. El-Serag HB. Hepatocellular carcinoma. N. Engl. J. Med. 2011; 365:1118-27.

9. Polesel J, Zucchetto A, Montella M, et.al. The impact of obesity and diabetes mellitus on the risk of hepatocellular carcinoma. Ann. Oncol. 2009; 20:353-7.

10. WHO Expert Consultation. Appropriate body-mass index for Asian populations and its implications

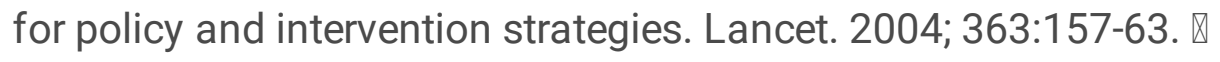

11. Liu LN, Miaskowski C, Wang JS, et.al. Accuracy of body mass index to determine obesity in women with breast cancer: an observational study of Taiwanese sample. Int J Nurs Stud. 2010; 47:994-1000.

12. Liu Y, Tong G, Tong W, et.al. Can body mass index, waist circumference, waist-hip ratio and waistheight ratio predict the presence of multiple metabolic risk factors in Chinese subjects? BMC Public Health. 2011 Jan 13; 11:35.

13. World Health Organization.Global data on body mass index. BMI classification. http//apps.who.int/bmi/index.jsp (accessed 3 December 2009).

14. Uka K, Aikata H, Takaki S, et.al. Clinical features and prognosis of patients with extrahepatic metastases from hepatocellular carcinoma. World J. Gastroenterol. 2007; 13:414-20.

15. Uchino K, Tateishi R, Shiina S, et.al. Hepatocellular carcinoma with extrahepatic metastasis: clinical features and prognostic factors. Cancer. 2011; 117:4475-83.

16. Xin Yu, Hong Yu a, Xiangming Fang. Yu X, Yu H, Fang XM. The impact of body mass index on shortterm surgical outcomes after laparoscopic hepatectomy, a retrospective study. BMC Anesthesiology 2016; 16:29: DOI 10.1186/s12871-016-0194-1.

17. 17. Cai XJ, Li ZY, Zhang YL, et.al. Laparoscopic liver resection and the learning curve: a 14-year, single-center experience. Surg Endosc. $2014 ; 28(4): 1334-41$.

18. Zhou Y, Wu L, Li X, et.al. Outcome of laparoscopic colorectal surgery in obese and nonobese patients: a meta-analysis. Surg. Endosc 2012; 26 (3): 783-789.

19. Duan XF, Tang P, Shang XB, et.al. High body mass index worsens survival in patients with esophageal squamous cell carcinoma after esophagectomy. Dig Surg. 2017; 34:319-27. 》

20. Troisi RI, Montalti R, Van Limmen JG, et.al. Risk factors and management of conversions to an open approach in laparoscopic liver resection: analysis of 265 consecutive cases. HPB. 2014; 16(1):7582.

21. Mathur AK, Ghaferi AA, Osborne NH, et.al. Body mass index and adverse perioperative outcomes following hepatic resection. J. Gastrointest. Surg. 2010; 14:1285-91. \ 
22. Rui R, Lou J, Zou L, Zhong R, et.al. Excess body mass index and risk of liver cancer: a nonlinear doseresponse meta-analysis of prospective studies. PLoS ONE. 2012;7(9), e44522.

23. Nozoe T, Kohno M, Iguchi T, et.al. Analysis of the impact of the body mass index in patients with gastric carcinoma. Surg. Today 2012; 42(10):945-9. Q

24. Kim JM, Park JH, Jeong SH, et.al. Relationship between low body mass index and morbidity after gastrectomy for gastric cancer. Ann Surg Treat Res 2016; 90:207-12.『

25. Uchino K, Tateishi R, Shiina S, et.al. Hepatocellular carcinoma with extrahepatic metastasis: clinical features and prognostic factors. Cancer. 2011; 117:4475-83.

26. Health, United States, 2015: With special feature on racial and ethnic health disparities. Hyattsville(MD); National Center for Health Statistics(US), 2016: 461.

27. GBD 2015 Obesity Collaborators, Afshin A, Forouzanfar MH, Reitsma MB, et al. Health Effects of Overweight and Obesity in 195 Countries over 25 Years. N. Engl. J. Med. 2017; 377:13-27.

28. Shimada H, Fukagawa T, Haga Y, et.al. Does postoperative morbidity worsen the oncological outcome after radical surgery for gastrointestinal cancers? A systematic review of the literature. Ann Gastroenterol Surg 2017; 1:11-23.

29. Goldfarb Y, Sorski L, Benish M, et.al. Improving postoperative immune status and resistance to cancer metastasis: a combined perioperative approach of immunostimulation and prevention of excessive surgical stress responses. Ann. Surg. 2011; 253:798-810.

30. Dunn GP, Old LJ, Schreiber RD. The immunobiology of cancer immunosurveillance and immunoediting. Immunity 2004; 21:137-48.

31. Sierzega M, Kolodziejczyk P, Kulig J, Polish Gastric Cancer Study Group. Impact of anastomotic leakage on long- term survival after total gastrectomy for carcinoma of the stomach. Br J Surg 2010; 97:1035-42.

\section{Figures}




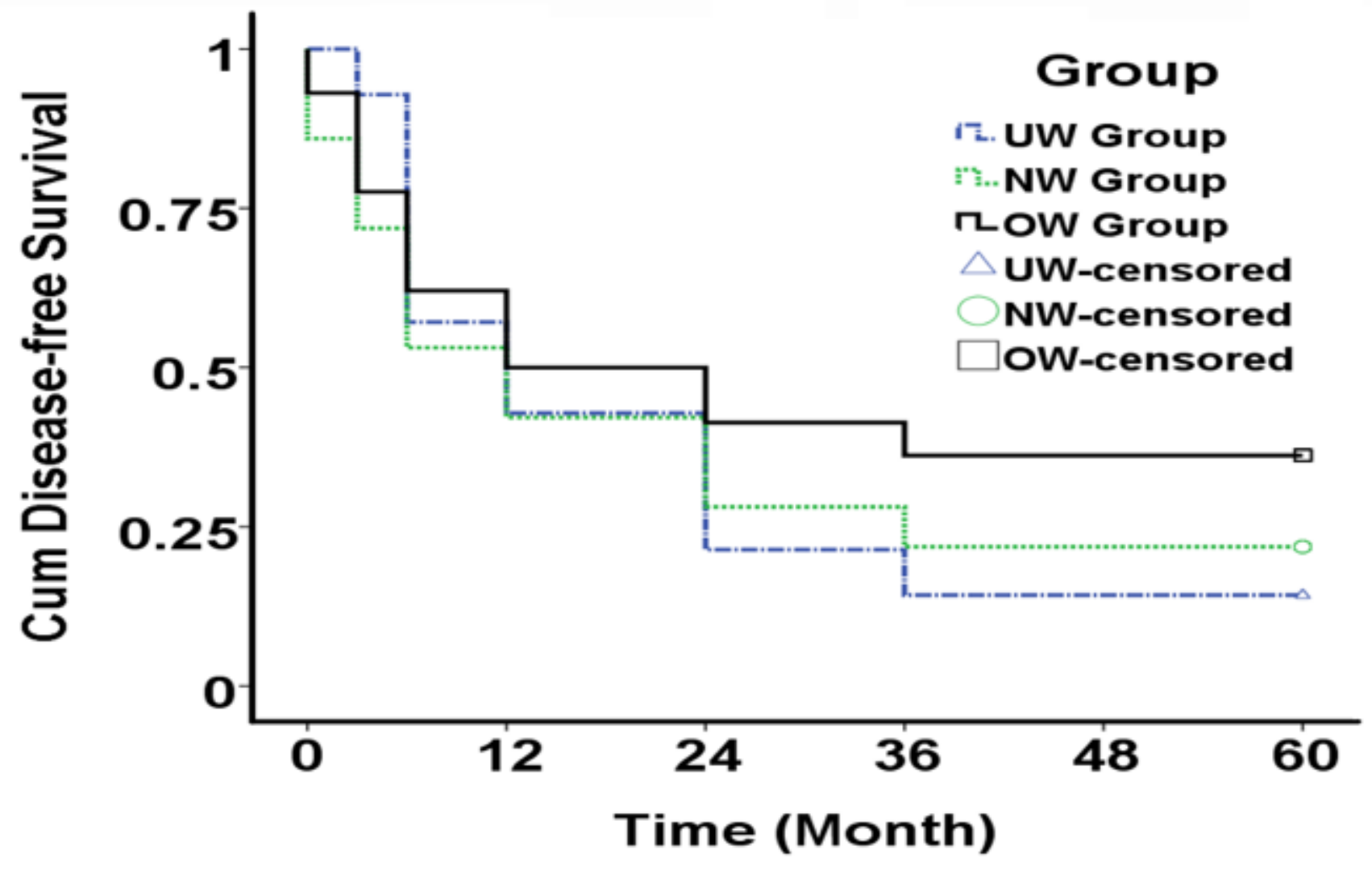

Figure 1

Disease free survival among $B M l<18.5 \mathrm{~kg} / \mathrm{m} 2,18.5 \leq \mathrm{BMl}<23 \mathrm{~kg} / \mathrm{m} 2$ and $\mathrm{BMI} \geq 23 \mathrm{~kg} / \mathrm{m} 2$ of the patients with liver cancer 


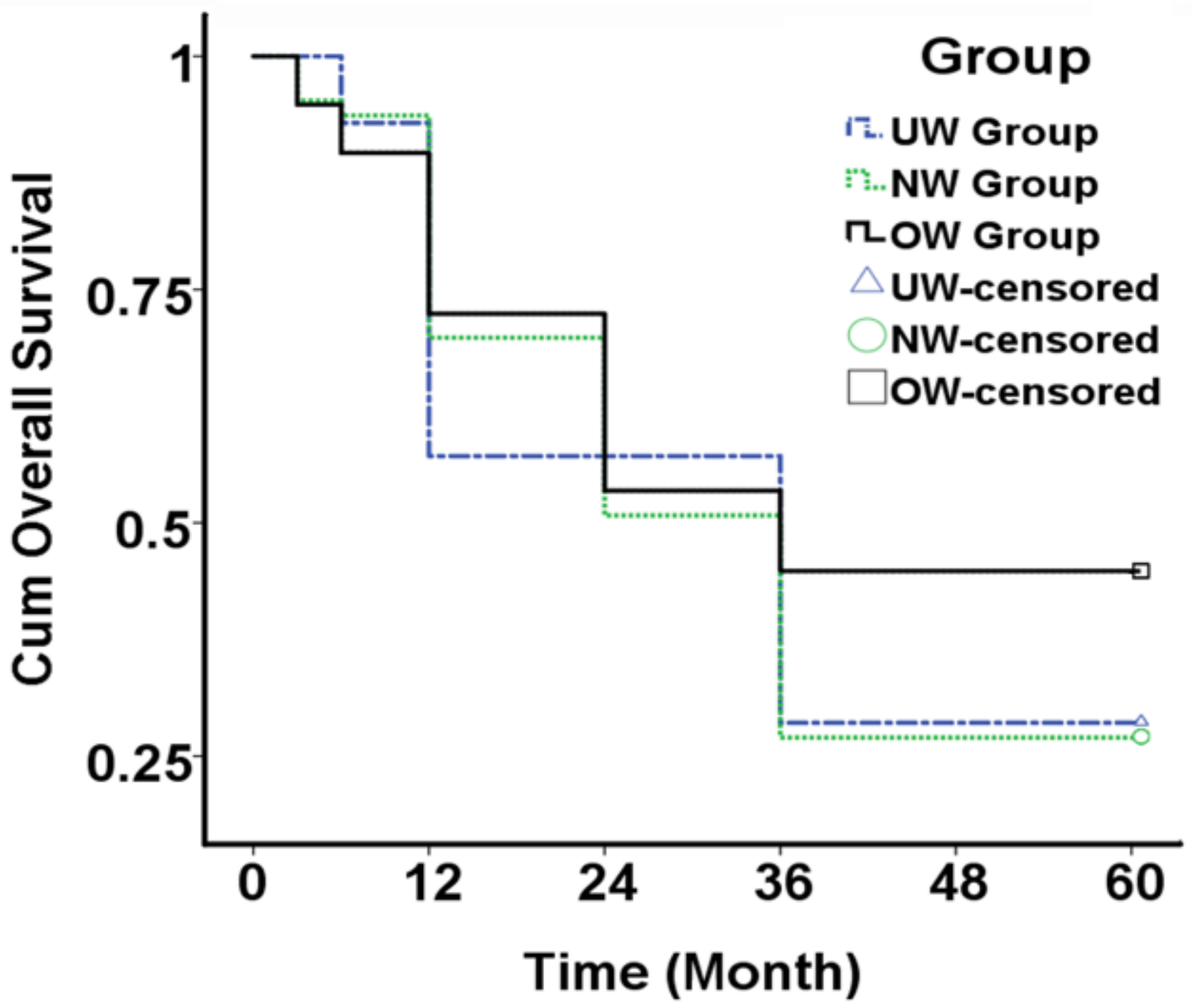

Figure 2

Overall survival according among $B M K 18.5 \mathrm{~kg} / \mathrm{m} 2,18.5 \leq \mathrm{BM}<23 \mathrm{~kg} / \mathrm{m} 2$ and $\mathrm{BMI} \geq 23 \mathrm{~kg} / \mathrm{m} 2$ of the patients with liver cancer 